\title{
Pengaruh Brand Awareness dan Kepuasan Pelanggan Terhadap Loyalitas Pelanggan

\author{
(Studi pada Pelanggan Produk Spring bed Merek Kangaroo di Toko Prioritas, \\ Pekanbaru)
}

\author{
Amelia, Rezi Erdiansyah \\ ameliabigael12@gmail.com,rezie@fikom.untar.ac.id \\ Fakultas Ilmu Komunikasi Universitas Tarumanagara
}

\begin{abstract}
:
This study is to exemine the effect of brand awareness and customer satisfaction on customer loyalty spring bed at Prioritas, Pekanbaru. This study using quantitative methods with survey techniques in data collection. Sampling technique is probability using a simple random sampling technique, where each member of the population has the same oppurtunity to be examined. The population of the sampling are 125 respondens. The result suggest that brand awareness and customer satisfaction significandly influencing customer loyalty. The result of this study indicate that is a very strong influence of brand awareness and customer satisfaction with customer loyalty. Determination result test also showing 82,5\% of brand awareness variable and customer satisfaction could give influence for customer loyalty variable, and the left 17,5\% could be effected by other factors.
\end{abstract}

Keyword: Brand Awareness, Customer Satisfaction, Customer Loyalty

\begin{abstract}
Abstrak:
Penelitian ini membahas mengenai pengaruh brand awareness dan kepuasan pelanggan terhadap loyalitas pelanggan produk spring bed merek Kangaroo di Toko Prioritas, Pekanbaru. Metode penelitian yang digunakan adalah metode kuantitatif dengan menggunakan teknik survei dalam pengumpulan data. Teknik sampling yang digunakan probability sampling dengan menggunakan teknik sampling random sederhana, dimana setiap anggota populasi memiliki peluang yang sama untuk diteliti. Penelitian menggunakan 125 responden sebagai sampel. Hasil penelitian ini menunjukkan bahwa terdapat pengaruh yang sangat kuat dari brand awareness dan kepuasan pelanggan terhadap loyalitas pelanggan. Hasil uji determinasi menunjukkan 82,5\% variabel brand awareness dan kepuasan pelanggan dapat memberikan pengaruh terhadap variabel loyalitas pelanggan, sedangkan sisanya sebanyak $17,5 \%$ dapat disebabkan oleh faktor-faktor lain.
\end{abstract}

Kata Kunci: Brand Awareness, Kepuasan Pelanggan, Loyalitas Pelanggan

\section{Pendahuluan}

Di era sekarang ini, dapat dilihat bahwa industri makanan dan konveksi diminati banyak orang. Tetapi tidak hanya itu saja, industri furniture seperti spring bed pun tidak kalah, ia juga berkembang dengan pesat. Semakin ketatnya persaingan dalam industri spring bed, menuntut para produsen atau pelaku usaha untuk mampu bersaing dengan para kompetitor dalam menjaga eksistensi yang dimiliki perusahaan 
dan juga untuk memperoleh keuntungan. Produsen harus memiliki strategi pemasaran yang tepat untuk produk yang diproduksi misalnya dengan beriklan di media cetak atau media luar ruang seperti reklame, spanduk, dan lain-lain dengan tujuan agar merek produk tersebut dapat disadari, diketahui, dan dikenali oleh banyak orang. Menurut Durionto (2004: 29), karena umumnya pelanggan cenderung membeli produk dengan merek yang sudah mereka kenal atas dasar keamanan, kenyamanan, dan lain-lain.

Selain itu, produk yang diproduksi juga harus memiliki kualitas yang bagus dan kualitas jasa/ layanan yang diberikan sesuai dengan harapan pelanggan, sehingga dapat menimbulkan kepuasan pelanggan. Suatu pelanggan dapat dikatakan puas, ketika kinerja produk yang dibeli sesuai dengan apa yang diharapkan. Setelah pelanggan puas, pelanggan akan setia terhadap produk, lalu akan merekomendasikan kepada orang lain atas dasar pengalamannya, dan akan melakukan pembelian ulang (Kotler dan Amstrong, 2004: 793-794). Dengan ini, dapat menciptakan pelanggan yang loyal. Loyalitas pelanggan timbul dari kepuasan pelanggan terhadap produk yang ditawarkan.

Kangaroo spring bed merupakan merek tempat tidur yang memberikan kenyamanan dengan kualitas yang baik pada pemakainya, yang diproduksi oleh PT. Anugrah Karya Aslindo sejak tahun 1998 di Pekanbaru. Perusahaan ini menawarkan dan menjual produknya ke berbagai toko-toko furniture yang ada di Pekanbaru, salah satunya adalah toko PT. Prioritas yang terletak di Jalan Tuanku Tambusai No. 94, 96, 98 yang merupakan perusahaan ritel yang berkembang dengan pesat di Pekanbaru dan juga toko tersebut memiliki penjualan Kangaroo Spring bed paling banyak dibandingkan toko lain. Dengan ini, penulis ingin mengetahui seberapa besar pengaruh brand awareness dan kepuasan pelanggan terhadap loyalitas pelanggan pada produk spring bed merek Kangaroo di Toko Prioritas, Pekanbaru.

Landasan Teori, Brand Awareness: Menurut David A.Aaker (1991: 68) kesadaran merek adalah kemampuan pembeli dalam mengenal dan mengingat bahwa suatu merek adalah anggota dari kategori suatu produk. Menurut Durionto, dkk (2004: 29) dalam Ariyan (2012) kesadaran merek adalah anggota penyusun ekuitas merek yang sangat penting. Karena umumnya pelanggan cenderung membeli produk dengan brand yang sudah mereka kenal atas dasar keamanan, kenyamanan, dan lainlain. Brand Awareness memiliki empat tingkatan, yaitu unware of a brand, brand recognation, brand recall, dan top of mind (Aaker, 1991:69). Untuk mengetahui seberapa jauh konsumen sadar terhadap merek mengacu pada teori Kriyantono (2006: 26), dalam Iskandar dan Sari (2017: 284) sebagai berikut: recognition, recall, purchase, consumption.

Kepuasan Pelanggan: Kepuasan dapat diartikan sebagai upaya untuk membuat sesuatu memadai. Kotler, 1994 (dalam Nasution, 2004: 104) mengatakan kepuasan pelanggan adalah tingkat perasaan pelanggan setelah membandingkan kinerja produk yang dirasakan dibandingkan dengan harapannya. Jadi, jika kinerja produk berada dibawah harapannya, maka pelanggan tidak puas, tetapi jika kinerja produk memenuhi harapannya maka pelanggan akan puas, dan jika kinerja produk melebihi harapannya, maka pelanggan akan amat sangat puas (Kotler \& Amstrong 2004: 793). Penelitian ini memiliki indikator yang mengacu pada teori Kotler dan Amstrong (2004: 793-794) yang meliputi: puas terhadap produk, setia terhadap produk, merekomendasikan, dan melakukan pembelian ulang.

Loyalitas Pelanggan: Sheth \& Mittal, 2004 (dalam Tjiptono, 2014: 393), loyalitas pelanggan adalah keterikatan pelanggan terhadap suatu merek, toko, atau 
Amelia, Rezi Erdiansyah: Pengaruh Brand Awareness dan Kepuasan Pelanggan Terhadap Loyalitas Pelanggan (Studi pada Pelanggan Produk Spring bed Merek Kangaroo di Toko Prioritas, Pekanbaru)

pemasok, yang timbul dari sikap positif dan pembelian ulang secara konsisten. Griffin (2003: 31) menyatakan bahwa, pelanggan yang loyal adalah orang yang melakukan pembelian ulang secara teratur, membeli antarlini produk dan jasa, merekomendasikan kepada orang lain, dan menunjukkan kekebalan terhadap tarikan dari pesaing. Tjiptono (2014: 392 \& 406-407) mengemukakan beberapa indikator yang penulis gunakan untuk mengukur loyalitas pelanggan, yaitu: pembelian ulang, tetap memilih merek, yakin terhadap merek, dan merekomendasikan.

\section{Metode Penelitian}

Metode yang penulis gunakan dalam penelitian ini adalah metode penelitian kuantitatif dengan jenis survey. Teknik sampling yang digunakan adalah probability sampling dengan menggunakan teknik sampling random sederhana, dimana setiap anggota populasi berpeluang yang sama untuk diteliti.. Pengumpulan data dengan menyebarkan kuisioner kepada 125 pelanggan dengan karakteristik usia diatas 21 tahun yang pernah membeli atau memakai produk spring bed merek Kangaroo di Toko Prioritas Jalan Tuanku Tambusai di Pekanbaru.

Data primer yang digunakan penulis adalah kuisioner yang diisi oleh para pelanggan yang membeli spring bed Kangaroo di Toko Prioritas, sedangkan data sekunder yang digunakan adalah memalui sumber buku dan jurnal yang membahas mengenai kasus yang relevan dengan penelitian.

Penulis menggunakan uji validitas dan uji reliabilitas untuk mengetahui bahwa data yang diperoleh valid atau tidak dan terpercaya atau tidak. Sedangkan untuk mengetahui apakah data tersebut memenuhi uji normalitas, penulis menggunakan Normal P-P Plot yang pada prinsipnya dapat dilihat dari penyebaran titik pada garis diagonal grafik.

Teknik pengolahan dan analisis data menggunakan uji koefisien korelasi dan determinasi, analisis regresi linear berganda, uji T, dan uji F. Uji analisis koefisien korelasi bertujuan untuk mengukur seberapa kuat pengaruh hubungan variabel independent terhadap variabel dependent, sedangkan uji koefisien determinasi digunakan untuk melihat seberapa besar persentase variabel bebas (X) yang dapat berpengaruh terhadap variabel terikat $(\mathrm{Y})$. Adapun hipotesis yang digunakan penulis dalam penelitian ini adalah sebagai berikut:

$\mathrm{Ha}_{1}$ : Terdapat pengaruh brand awareness terhadap loyalitas pelanggan.

$\mathrm{Ho}_{1}$ : Tidak terdapat pengaruh brand awareness terhadap loyalitas pelanggan.

$\mathrm{Ha}_{2}$ : Terdapat pengaruh kepuasan pelanggan terhadap loyalitas pelanggan.

$\mathrm{Ho}_{2}$ : Tidak terdapat pengaruh kepuasan pelanggan terhadap loyalitas pelanggan.

$\mathrm{Ha}_{3}$ : Terdapat pengaruh brand awareness dan kepuasan pelanggan terhadap loyalitas pelanggan.

$\mathrm{Ho}_{3}$ : Tidak terdapat pengaruh brand awareness dan kepuasan pelanggan terhadap loyalitas pelanggan.

\section{Hasil Temuan dan Diskusi}

Uji Validitas: Untuk melihat bahwa butir pernyataan pada kuisioner valid atau tidak digunakan patokan 0,2 lalu dibandingkan dengan angka yang ada pada kolom Corrected Item-Total Correlation (Nisfiannoor, 2009: 298). Berdasarkan hasil pengujian, penulis menyimpulkan bahwa hasil uji validitas terhadap 15 butir pernyataan dari variabel (X1) kesadaran merek (brand awareness), 14 butir 
pernyataan variabel (X2) kepuasan pelanggan, dan 12 butir pernyataan variabel (Y) loyalitas pelanggan pada produk Kangaroo spring bed dinyatakan valid karena > 0,2.

Uji Reliabilitas: Reliabilitas artinya dapat dipercaya. Menurut Nunnaly (1994) dalam Ghozali (2018: 46) suatu kuisioner dikatakan reliabel apabila hasil alpha $\geq 0,7$ dan sebaliknya. Hasil pengujian pada variabel brand awareness menunjukkan hasil 0,943, hasil variabel kepuasan pelanggan 0,902 dan hasil variabel loyalitas pelanggan sebesar 0,868. Ini menunjukkan bahwa setiap variabel dinyatakan reliabel atau dapat dipercaya.

Uji Normalitas: Berdasarkan hasil pengujian, menunjukkan bahwa data menyebar disekitar garis diagonal dan searah garis diagonal dengan arah hubungan koefisien positif. Dengan ini, dapat dinyatakan bahwa model regresi variabel terikat loyalitas pelanggan terhadap produk merek Kangaroo Spring bed di Toko Prioritas Jalan Tuanku Tambusai di Pekanbaru telah memenuhi uji normalitas.

Uji Hipotesis:

a. Analisis Regresi Linear Berganda

Adapun persamaan rumus regresi linear berganda dalam penelitian ini adalah:

$\mathrm{Y}=7,713+0,112 \mathrm{X} 1+0,589 \mathrm{X} 2$.

Konstanta 7,713 artinya jika nilai brand awareness dan kepuasan pelanggan tidak berubah (0), maka loyalitas pelanggan memiliki nilai yang sama dengan konstanta, yaitu 7,713. Nilai 0,112 artinya apabila variabel brand awareness (X1) memiliki perubahan/ peningkatan, maka nilai loyalitas pelanggan juga mengalami perubahan sebesar 0,112 satuan. Nilai 0,589 artinya apabila variabel kepuasan pelanggan (X2) memiliki perubahan/ peningkatan, maka loyalitas pelanggan juga mengalami perubahan sebesar 0,589 satuan. Dengan ini dapat disimpulkan jika ada perubahan/ peningkatan pada brand awareness dan kepuasan pelanggan maka loyalitas pelanggan juga akan berubah/ meningkat. Sebaliknya, jika tidak ada perubahan/ peningkatan pada brand awareness dan kepuasan pelanggan, maka loyalitas pelanggan juga tidak berubah/meningkat.

b. Uji T

Menurut Ghozali (2006: 84) uji statistik T menunjukkan sejauh mana pengaruh suatu variabel independent (bebas) terhadap variabel dependent (terikat) dengan tingkat probabilitas $(\alpha)=0,05$. Apabila sig $<0,05$ berarti Ha diterima artinya bahwa variabel independent memengaruhi variabel dependent dan sebaliknya. Dengan ini didapat hasil uji T, sebagai berikut:

Hipotesis 1 : untuk melihat variabel brand awareness (X1) terdapat nilai t sebesar 2,577 dengan nilai sig sebesar 0,011 <0,05, artinya Ha diterima dan Ho ditolak. Dengan ini menunjukkan bahwa variabel brand awareness berpengaruh terhadap loyalitas pelanggan.

Hipotesis 2 : untuk variabel kepuasan pelanggan (X2) terdapat nilai t sebesar 11,835 dengan nilai sig sebesar $0,000<0,05$, artinya variabel kepuasan pelanggan berpengaruh terhadap loyalitas pelanggan.

c. Uji F

Derajat yang digunakan untuk mengukur uji $\mathrm{F}$ adalah 0,05 . Apabila nilai sig $>$ 0,05 maka dapat dikatakan bahwa data penelitian tidak dapat digunakan untuk memprediksi variabel dependent, dan sebaliknya. Hasil pengujian $\mathrm{F}$ adalah sebagai berikut:

Hipotesis 3 : diperoleh hasil $\mathrm{f}$ sebesar 288,257 dengan nilai sig $0,000<0,05$; maka Ha diterima dan Ho ditolak, artinya terdapat pengaruh brand awareness dan kepuasan pelanggan terhadap loyalitas pelanggan. 
Amelia, Rezi Erdiansyah: Pengaruh Brand Awareness dan Kepuasan Pelanggan Terhadap Loyalitas Pelanggan (Studi pada Pelanggan Produk Spring bed Merek Kangaroo di Toko Prioritas, Pekanbaru)

Penelitian yang penulis teliti memiliki tiga variabel, yaitu variabel independent (bebas) yang terdiri dari variabel Brand Awareness dan Kepuasan Pelanggan dan variabel dependent (terikat) yang terdiri dari variabel Loyalitas Pelanggan. Penelitian ini menggunakan metode kuantitatif berupa survey dengan menggunakan kuisioner sebagai pengumpulan data yang bertujuan untuk melihat pengaruh brand awareness dan kepuasan pelanggan terhadap loyalitas pelanggan produk spring bed merek Kangaroo di Toko Prioritas, Pekanbaru.

Penulis menggunakan sampel sebanyak 150 responden, tetapi hanya 125 kuisioner yang kembali terisi sesuai kriteria. Hasil pengolahan data yang penulis gunakan adalah program SPSS Ver. 23. Hasil uji statistik menyatakan produk Kangaroo spring bed memiliki pengaruh kesadaran merek dan kepuasan pelanggan yang sangat kuat terhadap loyalitas pelanggan yang membeli produk tersebut di Toko Prioritas, Pekanbaru. Data ini diukur berdasarkan pernyataan indikator dalam dimensi setiap variabel. Menurut Kriyantono (2006: 26) terdapat dimensi yang digunakan untuk mengetahui sejauh mana konsumen sadar terhadap merek, yaitu recognition, recall, purchase, comsumption. Dimensi kepuasan pelanggan mengacu pada teori Kotler dan Amstrong (2004: 793), yaitu puas terhadap produk, setia terhadap produk, merekomendasikan, dan melakukan pembelian ulang. Sedangkan untuk dimensi loyalitas pelanggan, menggunakan dimensi menurut Tjiptono (2014: $392 \& 403$ ) yaitu pembelian ulang, tetap memilih merek, yakin terhadap merek, dan merekomendasikan.

Berdasarkan hasil uji validitas, 41 butir pernyataan pada brand awareness (15), kepuasan pelanggan (14), dan loyalitas pelanggan (12) dinyatakan valid karena nilai corrected item-total correlation $>0,2$. Hasil uji reliabilitas pada variabel brand awareness, kepuasan pelanggan, dan loyalitas pelanggan dinyatakan reliabel karena angka pada cronbach's alpha $>0,7$. Hasil dari asumsi klasik juga menunjukkan bahwa model regresi variabel terikat loyalitas pelanggan terhadap produk merek Kangaroo spring bed telah memenuhi uji normalitas karena datanya menyebar disekitar garis diagonal dengan hubungan koefisien positif.

Hasil dari uji regresi linear berganda, menyatakan bahwa apabila brand awareness dan kepuasan pelanggan mengalami perubahan/ peningkatan maka loyalitas pelanggan terhadap merek produk juga akan berubah/ meningkat dan sebaliknya, jika brand awareness dan kepuasan pelanggan tidak mengalami perubahan/ peningkatan maka loyalitas pelanggan juga tidak berubah/ meningkat. Hasil uji hipotesis menyatakan bahwa variabel brand awareness dan kepuasan pelanggan berpengaruh secara signifikan terhadap loyalitas pelanggan pada produk Kangaroo spring bed di Toko Prioritas Pekanbaru.

Di antara variabel independent (bebas) yaitu brand awareness dan kepuasan pelanggan, variabel yang paling berpengaruh terhadap loyalitas pelanggan adalah kepuasan pelanggan karena memiliki nilai beta paling besar $(0,768)$ daripada variabel brand awareness. Hasil mean per dimensi variabel (X1) brand awareness menunjukkan bahwa dimensi purchase yang lebih banyak dipilih oleh responden dan untuk meaan per dimensi variabel (X2) kepuasan pelanggan menunjukkan bahwa dimensi puas terhadap produk yang lebih banyak dipilih oleh responden. Sedangkan untuk mean per dimensi variabel (Y) loyalitas pelanggan menunjukkan bahwa dimensi tetap memilih merek yang lebih banyak dipilih oleh responden.

Di antara ketiga variabel yaitu variabel brand awareness, kepuasan pelanggan, dan loyalitas pelanggan memiliki hubungan yang signifikan. Jika pelanggan sadar akan adanya merek produk akan memunculkan minat beli dan akan selanjutnya akan 
melakukan keputusan pembelian. Setelah pelanggan membeli produk dan merasakan kualitas produk atau jasa yang diberikan, pelanggan akan puas jika kinerja produk yang ia beli sesuai dengan harapannya. Dengan demikian, maka akan tercipta loyalitas pelanggan terhadap suatu produk.

\section{Simpulan}

Berdasarkan hasil penelitian, peneliti menarik kesimpulan bahwa brand awareness dan kepuasan pelanggan terhadap loyalitas pelanggan yang membeli produk Kangaroo spring bed di Toko Prioritas, Pekanbaru memiliki tingkat hubungan yang sangat tinggi. Terdapat pengaruh yang signifikan antara brand awareness terhadap loyalitas pelanggan produk spring bed Kangaroo di Toko Prioritas, Pekanbaru dan juga terdapat pengaruh signifikan antara kepuasan pelanggan terhadap loyalitas pelanggan spring bed Kangaroo di Toko Prioritas, Pekanbaru. Dengan ini dapat disimpulkan bahwa dari hasil uji hipotesis menunjukkan diantara variabel brand awareness dan kepuasan pelanggan berpengaruh signifikan terhadap loyalitas pelanggan. Hasil uji linear berganda menunjukkan jika brand awareness dan kepuasan pelanggan mengalami perubahan/ peningkatan, maka loyalitas pelanggan terhadap produk Kangaroo spring bed juga akan berubah/ meningkat dan sebaliknya jika brand awareness dan kepuasan pelanggan tidak mengalami perubahan/ peningkatan, maka loyalitas pelanggan terhadap porduk Kangaroo spring bed juga tidak akan berubah/ meningkat.

Dalam penelitian ini, peneliti menyarankan kepada produsen Kangaroo spring bed untuk bisa meningkatkan strategi promosinya agar merek kangaroo lebih dikenal lagi oleh masyarakat, selain itu kualitas produk dan jasa juga ditingkatkan. Untuk distributor Toko Prioritas juga agar bisa meningkatkan kualitas jasa/ pelayanan yang diberikan kepada pelanggan agar pelanggan puas dan akan loyal membeli produk Kangaroo spring bed di toko tersebut. Terakhir, saran kepada peneliti dimasa mendatang agar dapat menyempurnakan, memperkuat dan mengembangkan penelitian ini.

\section{Ucapan Terima Kasih}

Penulis mengucapkan terima kasih kepada Bapak Rezi Erdiansyah, M.Si selaku pembimbing, kepada dosen-dosen Fakultas Ilmu Komunikasi Universitas Tarumanagara, kepada orangtua yang selalu mendoakan penulis, dan kepada temanteman atau pihak-pihak yang sudah membantu proses berlangsungnya peneitian sampai pada pembuatan jurnal ini.

\section{Daftar Pustaka}

Aaker, David. A. (1991). Managing Brand Equity. New York: The Free Press Durionto, dkk. (2004). Brand Equity Ten, Strategi Memimpin Pasar. Jakarta: Gramedia Pustaka Utama

Ghozali, Imam. (2006). Aplikasi Analisis Multivariate dengan Program SPSS. Edisi 4. semarang: Badan Penerbit Universitas Diponegoro. .(2018). Aplikasi Analisis Multivariate dengan Program SPSS. Edisi 9. Semarang: Badan Penerbit - Undip 
Amelia, Rezi Erdiansyah: Pengaruh Brand Awareness dan Kepuasan Pelanggan Terhadap Loyalitas Pelanggan (Studi pada Pelanggan Produk Spring bed Merek Kangaroo di Toko Prioritas, Pekanbaru)

Griffin, Jill. (2003). Customer Loyalty: Menumbuhkan dan Mempertahankan Kesetiaan Pelanggan. Dialihbahasakan oleh Dwi Kartini Yahya. Jakarta: Erlangga

Kotler dan Amstrong. (2004). Dasar-dasar Pemasaran. Jilid 2, Edisi 9. Jakarta: Indeks

Kriyantono, Rachmat. (2006). Teknik Praktis Riset Komunikasi. Jakarta: PT. Kencana Perdana

Nasution. (2004). Manajemen Jasa Terpadu. Bogor: Ghalia Indonesia

Nisfiannoor, Muhammad. (2009). Pendekatan Statistik Modern Untuk Ilmu Sosial. Jakarta: Salemba Humanika

Tjiptono, Fandy. (2014). Pemasaran Jasa: Prinsip, Penerapan, dan Penelitian. Jogyakarta: Andi OFFSET

Ariyan. (2013). Pengaruh Brand Awareness dan Kepercayaan Konsumen atas Merek Terhadap Keputusan Pembelian Ulang Minuman Aqua di Kota Padang. http://ejournal.unp.ac.id/students/index.php/mnj/article/download/151/138 , diunduh tanggal 7 September 2018

Iskandar dan Sari. (2017). The Effect Of Event And Publicity Toward Brand Awareness On Financial Service Authority (OJK). Jurnal Riset Manajemen dan Bisnis (JRMB), Vol. 2, September 2017. https://media.neliti.com/media/publications/259344-the-effect-of-event-andpublicity-toward-2eb42d60.pdf , diunduh tanggal 7 September 2018.

Nurullaili dan Wijayanto. (2013). Analisis Faktor-Faktor yang Mempengaruhi Loyalitas Konsumen Tupperware: Studi Pada Konsumen Tupperware di Uniersitas Diponegoro). https://ejournal.undip.ac.id/index.php/janis/article/download/5357/4814 diunduh tanggal 30 Oktober 2018. 